That is true, but, on the other hand, some are like Ivanchuk who absolutely refuses to play against computers now.

That's right, yes.

Why do you think that is? He has nothing to fear at the moment from computers.

I don't know: I don't know Ivanchuk that well. It might be something like the case of Valery Salov for one - he hates them. I'm also thinking of someone else who gets wild on the subject of computers. I am talking about the Danish Grandmaster Curt Hansen. You know how Hansen is when he gets on the subject of computers. He will never play one.

Do you think the programs that you have seen here are strong enough to be useful analytical tools for a Grandmaster like yourself?

I will better be able to answer this question when I actually start using one for that purpose. I'm getting ready to do that. But so far I have not. I think I certainly should be able to use the better ones here, and I'm looking forward to it.

Some people believe that when computers do become of Kasparov's strength and can win matches against the strongest human players in the world, that it would mean the end of chess. Do you believe that?

I don't think so. I think that human players will have several options but at that point they may become jaded - I mean jaded through the discovery that computers are that strong and it's not a living question anymore. Then they can just put the computer aside and play their own games. This prospect is somewhat analogous perhaps to the situation of the average club players, let's say those in the Manhattan Chess Club. Sometimes they show an interest in Grandmaster Tournaments but it's very easy, it seems, for them to switch from watching a Grandmaster tournament game and to go back to playing their own games. They don't make a connection and they don't say "Oh well, it's only me, I can't do that." It is like two separate parts of their experience. And the same might happen in the future when machines get very strong.

On balance, do you believe computers have been beneficial or detrimental to chess?

I think they are beneficial. They have extended our perspective on the game. Even, just in a theoretical way, I find it nice to know without further explanation that a Bishop and a Rook can beat two Knights in 230 moves, even if I can't do it (and I can't!). With regard to some of the computer database endings - it is very likely in queen and pawn endings I think - and other Grandmasters have told me the same - that they benefit from playing over the machine's methods of doing it. Quite a few players have told me they are better at it now. Of course that is not true with the Bishop and Rook against two Knights. I don't know anyone who claims to be able to do that, but it's fascinating that it is there to be done.

\title{
EXTRAPOLATION AND SPECULATION
}

\author{
David Levy ${ }^{1}$
}

London, England

\section{Introduction}

It has long been a popular pastime within the overlapping worlds of chess and computer chess for experts to predict when the time might come that a computer program would win a match against the human World Chess Champion. One of the earliest clairvoyants was Newborn (1979) who prophesied that "...it is highly

1 89, Constantine Road, London NW3 2LP, England. Email: DavidL@intrsrch.demon.co.uk 
probable that programs will be playing Master level chess by 1984, Grandmaster level chess by 1988 and better than any human by 1992 . (These are conservative estimates!)"

The first of these estimates was shown to be fully justified when BELLE achieved U.S. Master status in 1983, while Newborn's prediction for Grandmaster play was also proved amazingly accurate (in a sense) when DEEP THOUGHT shared first place at Long Beach 1988 with GM Tony Miles, ahead of several other Grandmasters. (DEEP THOUGHT defeated Bent Larsen in the process and won an exhibition tie-break game against Miles the following year.) Only in regard to the ultimate goal, defeating the human World Champion, was Newborn's original forecast unduly optimistic.

As time has moved on and with it our understanding of the magnitude of the problem, so the estimates of the experts have also moved on. Typically, strong chess-players have predicted later-rather-than-sooner dates, while the academics have been more optimistic.

\section{Extrapolation using "uncensored" data}

Estimates based on competitive results have been able to give us a hint of an objective insight into the progress made in this field (Levy, 1986). The sources for these estimates were various programs' best performance ratings in a given year - extrapolating this data has pinpointed with an uncanny accuracy the year in which Kasparov would first lose a tournament game to a computer program (Levy, 1994), albeit the two(!!) tournament games that he did lose during 1994 were both played at speeds very much faster than those of a World Championship-style match.

As recent testimony to the ability of programs to achieve performance ratings of strong Grandmaster calibre, which we may reasonably define as 2600 or over on the ELO scale (2700 or over on the USCF scale'), one can cite the examples of the ELO performance ratings of the top programs at this year's AEGON tournament in The Hague (Verbaan, 1995): CHESS GenIUS X (2662), M-CHESS PRO (2652), HIARCS (2631) and HiteCH (2600), as well as the even more impressive USCF performance rating of 2895 (equivalent to 2795 ELO) achieved by WCHESS at the 5th Harvard Cup tournament in Boston last year (Chabris and Kopec, 1994). But as one would expect, performance ratings achieved by computer programs are normally flattered by faster time controls, as was the case in both of these events. When a top program competes in a strong tournament where the rate of play is 40 -in-2 or similar, the humans tend to fare better. For example, FRITZ3 achieved "only" 2452 Elo in the recent tournament at Bad Godesberg, Germany, which was trumpeted as a great success for the program (Schulz, 1995). Sadly, there is as yet very little evidence from such tournaments to support the view that chess programs have genuinely passed the 2500 barrier (ELO), let alone 2600. In the author's opinion FRITZ3's 2452 is an accurate reflection of the genuine chess strength of today's top programs and so is found wanting.

\section{Extrapolation from "censored" data}

The above-mentioned data is based on sporadic results achieved at time controls which often differ markedly from the "classical" 40 moves in 2 hours. A more useful analysis of progress in playing strength would require data acquired under reasonably consistent circumstances. Although no suitable rating list exists which could be used to monitor progress by all of the best programs - based on their performances in tournaments - there is one guide which can serve as a steady measure. The Swedish rating list, published regularly in the ICCA Journal for over 10 years, is an impartial and reliable source of data on the strongest commercially-available chess programs. Their ratings are based on playing several hundred games by each program.

Progress during the past few years in the world of commercial chess programs is such, that there is now very little to choose in strength between the best of today's commercially-available programs and the products of the leading superchip and supercomputer programmers. Hence, although this was untrue a few

1 According to one member of the FIDE Qualifications Commission, the correct transformation from ELo ratings to USCF ratings seems to be 150 rather than 100 . Until such time as this is confirmed in print by a competent authority we shall continue to use the figure from conventional wisdom. 
years ago, the best commercial programs now provide a useful gauge as to how the very best programs are improving.

Plotting the rating of the top commercially-available programs against time, from December 1984 to June 1995 , indicates a fairly steady increase, averaging around 45 ELo points per year consistently. Assuming continuity of this rate, the strongest commercially-available programs will be of human World Championship calibre around the year A.D. 2003.

\section{Let us speculate}

It is fascinating to compare the extrapolation of performance with the informed opinions of members of the computer-chess fraternity. In 1989, during the 6th World Computer-Chess Championship in Edmonton, I conducted a survey (Levy and Newborn, 1991). Following the 8th World Championship in Hong Kong in May 1995, I again solicited opinions of many of the computer-chess cognoscenti. The question assumed that a match against the human World Champion would be played at the now "classic" rate of play - 40 moves in 2 hours, then 20 moves in 1 hour, then all remaining moves in 30 minutes. (This is the rate of play being used for the Kasparov v Anand match currently in progress.) It is intended to conduct similar surveys every three years until the fateful day arrives.

The opinions sought included:

- programmers of all the programs who competed in the World Computer-Chess Championship in Hong Kong;

- the highest-scoring human players at this year's AEGON tournament;

- all ICCA officials;

- $\quad$ a selected number of other distinguished members of the computer-chess fraternity;

- $\quad$ some chess journalists especially involved with progress in this field.

All of the answers received are included in the following results. (Anyone who was also surveyed in 1989 has their earlier prediction in parentheses.)

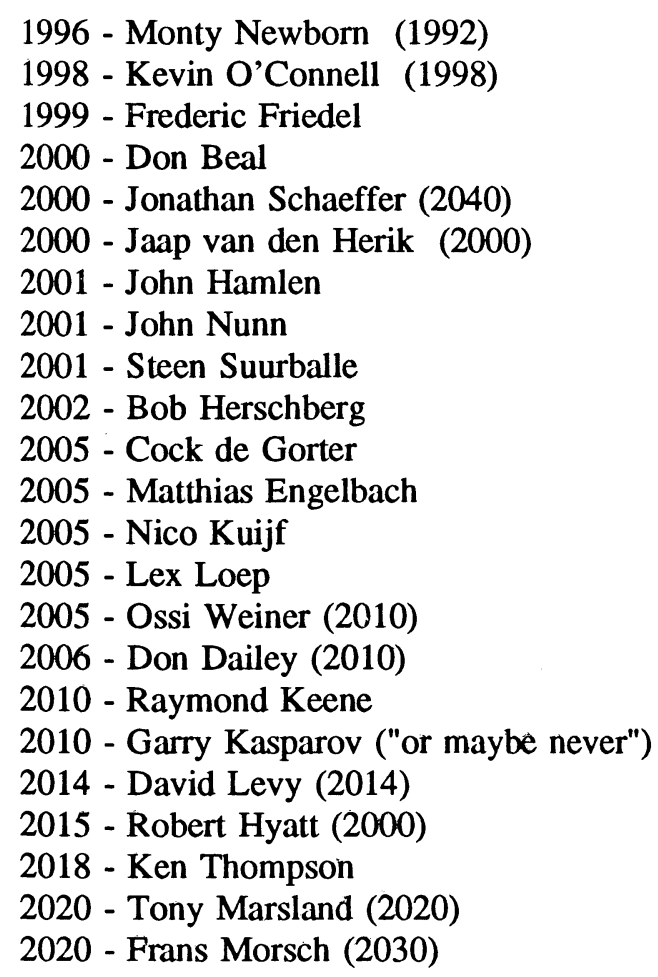


Quoting IGM John van der Wiel, we record: "I think this [the computer beating Kasparov] is unlikely to happen. Maybe the human World Champion can be defeated, if he goes wrong in style, as well may happen under current PCA usage. On the other hand, if a super-GM, keen on being a virus to any computer is to play the match, I believe chances are he will win." Confronting the 1989 predictions with those emanating in 1995 we find that in each survey there was only one doubtful Thomas, who denied that computers would ever go beyond the World Champion. The remaining 42 subjects of the 1989 survey showed an average estimate of the playing strength being over Kasparov by A.D. 2007.9; the remaining 23 of the 1995 survey had a collective estimate of A.D. 2005.9. The 10 subjects who responded to both surveys averaged 2011.4 in 1989 and 2007.4 in 1995.

\section{Summary}

- Occasional brilliant results have been achieved by chess programs at fast rates of play, but as yet, there is no sign of constantly high performance at 40 -in-2 or similar time controls.

- At the time of writing, the most impressive performance ever achieved by a program in a human tournament remains DEEP THOUGHT's tournament victory at Long Beach 1988. In a sense, therefore, there has been no real progress during the past 7 years in the power of the chess programs reputed strongest - a sobering thought!

- Over the past decade, there has been and continues to be a very steady progress in the strength of the best commercially-available programs. This trend shows no signs of abating.

- Expert opinion is generally more optimistic (from the programs' perspective) now than it was 6 years ago. There are large doubts about how long humans will reign supreme.

\section{References}

Chabris, C. and Kopec, D. (1994). Report on the Fifth Harvard Cup Human versus Computer Intel Chess Challenge. ICCA Journal, Vol. 17, No. 4, pp. 224-232.

Levy, D.N.L. (1986). When will Brute-Force Programs Beat Kasparov? ICCA Journal, Vol. 9, No. 2, pp. 81-86.

Levy, D.N.L. (1994). Straight on to Kasparov. ICCA Journal, Vol. 17, No. 2, p. 111.

Levy, D.N.L. and Newborn, M.M. (1991). How Computers Play Chess. Computer Science Press, New York.

Newborn, M.M. (1979). Recent Progress in Computer Chess. Advances in Computers, Vol. 18, pp. 59-117. Reprinted in Levy, D. (Editor), 1988). Computer Games I, pp. 154-205. Springer-Verlag, New York.

Schulz, A. (1995). FrITZ3 and the Grandmasters. ICCA Journal, Vol. 18, No. 1, pp. 45-48.

Verbaan, B. (1995). The $10^{\text {th }}$ AEgON Man-Machine Tournament. ICCA Journal, Vol. 18, No. 2, pp. 116123.

\section{Acknowledgement}

The author wishes to thank Frederic Friedel who provided the survey data for himself, Kasparov and Thompson. This data will appear in the forthcoming book Chess on the PC, The Game of Kings in Bits and Bytes, by Frederic Friedel $e t$ al. to be published by Simon \& Schuster. 